\title{
Specific antibodies to Anopheles gSG6-P1 salivary peptide to assess early childhood exposure to malaria vector bites
}

\author{
Papa M Drame ${ }^{1,2,8^{*}}$, Anne Poinsignon ${ }^{1}$, Célia Dechavanne ${ }^{3,4}$, Gilles Cottrell ${ }^{3,5}$, Manon Farce ${ }^{1}$, \\ Rodolphe Ladekpo ${ }^{6}$, Achille Massougbodji ${ }^{6,7}$, Sylvie Cornélie ${ }^{1}$, David Courtin ${ }^{3,4,6}$, Florence Migot-Nabias ${ }^{3,4}$, \\ André Garcia ${ }^{3,4}$ and Franck Remoué 1,2
}

\begin{abstract}
Background: The estimates of risk of malaria in early childhood are imprecise given the current entomologic and parasitological tools. Thus, the utility of anti-Anopheles salivary gSG6-P1 peptide antibody responses in measuring exposure to Anopheles bites during early infancy has been assessed.

Methods: Anti-gSG6-P1 lgG and lgM levels were evaluated in 133 infants (in Benin) at three (M3), six (M6), nine (M9) and 12 (M12) months of age. Specific lgG levels were also assessed in their respective umbilical cord blood (IUCB) and maternal blood (MPB).

Results: At M3, 93.98 and 41.35\% of infants had anti-gSG6-P1 lgG and IgM Ab, respectively. Specific median IgG and IgM levels gradually increased between M3 and M6 ( $p<0.0001$ and $p<0.001), M 6-M 9(p<0.0001$ and $p=0.085)$ and M9-M12 ( $p=0.002$ and $p=0.03$ ). These levels were positively associated with the Plasmodium falciparum infection intensity ( $p=0.006$ and 0.003 ), and inversely with the use of insecticide-treated bed nets ( $p=0.003$ and 0.3 ). Levels of specific $\lg G$ in the MPB were positively correlated to those in the IUCB $(R=0.73 ; p<0.0001)$ and those at M3 $(R=0.34 ; p<0.0001)$.
\end{abstract}

Conclusion: The exposure level to Anopheles bites, and then the risk of malaria infection, can be evaluated in young infants by assessing anti-gSG6-P1 lgM and lgG responses before and after 6-months of age, respectively. This tool can be useful in epidemiological evaluation and surveillance of malaria risk during the first year of life.

Keywords: Malaria, Salivary proteins, Biomarker of exposure, Anopheles bites, Maternal IgG transfer, Infants, Africa

\section{Background}

In the absence of effective vaccines, malaria control and prevention strategies are primarily based on the widespread use of effective drugs and vector control by insecticide-treated bed nets (ITNs) and indoor residual sprays [1-3]. Such interventions are associated with recent decline in malaria burden across a range of settings [4-6]. However, malaria incidence and risk are static or increasing in several African countries, including the Republic of

\footnotetext{
*Correspondence: papa.drame@nih.gov

${ }^{8}$ Present Address: Laboratory of Parasitic Diseases, NIAID, NIH, 4 Center Dr, Bethesda, MD 20892-0425, USA

Full list of author information is available at the end of the article
}

Benin, where the disease is still the first leading cause of child morbidity and mortality [7].

Naïve newborns are at increased risk of malaria infection during the first year of life in endemic areas [8-10]. Newborn exposure to malaria has traditionally been assessed using entomological and parasitological methods. However, these methods are labour-intensive and difficult to sustain especially in low transmission or exposure contexts $[11,12]$. In addition, these methods are typically used at the community level measure and do not target the individual [13]. Moreover, these methods typically exclude infants or newborns because of numerous ethical concerns $[14,15]$. Evaluating the risk of malaria 
in vulnerable infants is not only challenging but also requires new tools $[16,17]$.

Improving an understanding of human-Anopheles interactions can potentially provide a promising alternative $[18,19]$. Plasmodium spp. are transmitted to humans by the saliva of infected-female Anopheles mosquitoes during a blood meal. Injected mosquito salivary molecules facilitate the mosquito blood-feeding activity both by counteracting the human haemostatic and inflammatory reactions and by modulating its innate and adaptive immune responses [20, 21]. Following mosquito infecting as well as not-infecting bites, humans produce immunoglobulin G (IgG), M (IgM), and/or E (IgE) specific to injected mosquito salivary proteins [22-24]. Such humoral responses may be a marker of human exposure to vector bites and pathogens associated with mosquitoborne diseases [25-30].

A specific and highly conserved Anopheles gambiae salivary gland protein- 6 peptide 1 (gSG6-P1) antigen has been validated as a biomarker of Anopheles bites [13]. The anti-gSG6-P1 IgG response has been associated with local exposure level to An. gambiae s.l. and Anopheles funestus s.s. bites in zones with various transmission intensities [22, 31-33]. Moreover, anti-gSG6-P1 IgG responses have been shown to reflect the success of ITN-based [31, 34] and other [34] malaria vector control methods in that they diminish quite rapidly when exposure level drops [31]. However, this tool has not yet been tested in vulnerable young infants $(<1$-year old), therefore limiting its field application to malaria epidemiological studies or surveys.

The present study aimed to evaluate and to follow, during the first months of life, the acquisition level of human IgM and IgG responses to gSG6-P1 in southern Benin. Associations between specific gSG6-P1 IgG and IgM responses and parasitological and entomological parameters were evaluated. Whether mothers provide their infant with specific IgG through fetal-maternal transfer was also investigated.

\section{Methods}

\section{Study area}

The study was conducted in the district of Tori Bossito, a rural area located on the coastal plain of south Benin, $40 \mathrm{~km}$ northwest of Cotonou (the economic capital city). It is a sub-tropical area with an annual average rainfall of $1,100 \mathrm{~mm}$. There are two rainy seasons: April-July and October-November. The distribution of rainfalls, maximal during the two rainy seasons, was heterogeneous over the area. Average temperatures monthly varied between 27 and $31^{\circ} \mathrm{C}$. Anopheles gambiae s.s. and An. funestus, the most abundant anopheline species, are the major vectors for the transmission of Plasmodium falciparum, the major human malaria parasite in this region $[35,36]$. A recent study has described an average annual $P$. falciparum entomological inoculation rate of 15.5, with important time and space variations depending on villages [37]. Anopheles nili, Anopheles pharoensis and Anopheles leesoni, also locally present, are not yet associated with malaria transmission [36].

\section{Study design, population and sampling}

The study included nine villages (Avame Centre, Gbedjougo, Houngo, Anavie, Dohinoko, Gbetaga, Tori Cada Centre, Zebe, and Zoungoudo) distributed within three maternity hospitals (MHs: Avame, Cada and Gare) providing birth attendance and primary health care. Women who attended the maternity hospitals for antenatal care were asked to enter into the study and were recruited from anytime after the 7th month of pregnancy. Inclusion criteria were to: (1) live in one of the nine villages; (2) have no intention to move within the next 12 months; and, (3) plan to deliver at the maternity hospital. At delivery, maternal peripheral (MPB) and infant umbilical cord (IUCB) blood spots were collected on filter papers (Whatman No 1, Saint-Louis, MO, USA). After delivery, newborns were actively followed monthly over the subsequent 12 months. Capillary blood on filter paper and venous blood for smears (thick blood smears) were collected every 3 months (M3, M6, M9, and M12) for each live newborn to study the kinetics of antibody responses to gSG6-P1 peptide and to determine the presence and/or intensity of $P$. falciparum infections. Parasite density (parasitaemia) was calculated as the number of P. falciparum (99\% of identified Plasmodium) parasites per microlitre of blood; mean parasitaemia values $(x+1)$ were calculated. Mothers were asked to fill out questionnaires, including the use of ITNs and any clinical sign of the malaria for themselves and their babies. A birth cohort was then set up in July 2007 and recruitment performed until July 2008 as previously described [37].

The IRD Consultative Committee on Professional Conduct and Ethics (5 May, 2008) and the Ethical Committee of the Faculté des Sciences de la Santé of the University of Abomey-Calavi in Benin approved the study. All necessary permits were obtained for the described field studies. Informed written consent in French and Fon (major spoken language in the studied region) was obtained from the mothers.

Immunoassays were performed for 133 infants who completed a cord blood and the all four three-monthly blood spot samplings during the first 12 months of life follow-up.

\section{Prediction of spatiotemporal risk of malaria transmission}

Entomological data (by human landing catch of mosquitoes) were collected every 6 weeks on three successive 
nights from July 2007 to July 2008 at four catch houses (four indoors and four outdoors) in each village, as previously described [38]. A statistical model predicting the spatiotemporal transmission of malaria at the household level in all nine villages was then developed based on correlation results between Anopheles density and climatic/environmental factors [38], allowing comparisons between the individual risk of malaria transmission data from that model to anti-gSG6-P1 IgG and IgM Ab levels.

\section{Salivary peptide gSG6-P1}

The gSG6-P1 peptide was designed using bioinformatics to maximize its Anopheles specificity, synthesized and purified by Genepep SA (Saint Jean de Vedas, Herault, France). It was used for immunological tests (ELISA) as previously described $[13,32]$.

\section{Human IgG and IgM assays by indirect ELISA}

Standardized dried blood spots were eluted as previously described [28]. ELISAs were carried out on blood spot eluates to assay IgG and IgM responses to gSG6-P1. Briefly, Maxisorp plates (Nunc, Roskilde, Denmark) were coated with gSG6-P1 antigen $(20 \mu \mathrm{g} / \mathrm{mL})$ in PBS. Plates were blocked using $300 \mu \mathrm{L}$ of Protein-Free BlockingBuffer (Pierce, Thermo Scientific, France) for $45 \mathrm{~min}$ at $37^{\circ} \mathrm{C}$. Eluates were diluted $1 / 40(\operatorname{IgG})$ or $1 / 20(\operatorname{IgM})$ in PBS-Tween- $1 \%$ and incubated in duplicate at $4{ }^{\circ} \mathrm{C}$ overnight. Monoclonal mouse biotinylated $\mathrm{Ab}$ against human IgG or IgM (BD Pharmingen, San Diego, CA, USA) were incubated at 1/2,000 (IgG) or 1/500 (IgM) dilution. Peroxidase-conjugated streptavidin (Amersham, Les Ulis, France) was then added (1/2,000 for IgG and $1 / 500$ for IgM). Colorimetric development was carried out using ABTS (2,2'-azino-bis (3-ethylbenzothiazoline-6-sulfonic acid) diammonium; Sigma, St Louis, MO, USA) in $50 \mathrm{mM}$ citrate buffer ( $\mathrm{pH} 4$ ) containing $0.003 \% \mathrm{H}_{2} \mathrm{O}_{2}$. The optical density (OD) was measured at $405 \mathrm{~nm}$. In parallel, each test sample was assessed in a blank well containing no gSG6-P1 antigen (ODn). Results were expressed as the $\Delta \mathrm{OD}$ value: $\triangle \mathrm{OD}=\mathrm{ODx}-\mathrm{ODn}$, where ODx represents the mean of individual OD in both antigen wells. Anti-gSG6-P1 IgG and IgM levels were also assessed in 14 non-Anopheles exposed individuals (negative controls) from northern France to calculate the immune response threshold (TR). The TR was calculated by the following formula: $\mathrm{TR}=$ mean $\left(\Delta \mathrm{OD}_{\text {neg }}\right)+3 \mathrm{SD}=$ for IgG for IgM. In the present study an IgG responder had a $\Delta \mathrm{OD}_{\mathrm{IgG}}$ $>0.204$ and an IgM responder had a $\Delta \mathrm{OD}_{\mathrm{IgM}}>0.288$.

\section{Statistical analysis}

Data were analysed using R (version 2.14.1), and graphs were constructed with GraphPad Prism $5^{\circledR}$ software (San Diego, CA, USA). An simple linear mixed effect (LME) regression model was constructed to determine the correlation between anti-gSG6-P1 IgG or IgM response and each of potential epidemiological, biological and environmental factors, such as age (M3, M6, M9, and M12), gender (male $v s$ female), the season of sampling (end dry season: February to April; beginning rainy season: May to July; end rainy season: August to October; beginning dry season: November to January), P. falciparum prevalence (yes/no), P. falciparum infection intensity (continuous variable), bed net use (yes/no), and environmental risk of exposure (continuous variable). Then, a multivariate LME analysis was performed by including all explanatory variables that have shown significant (or close) $p$ value in the univariate (simple) model. In this multivariate model, two random intercepts at individual and village levels were introduced, correcting then biological inter-individual and inter-village variations. Two or more percentages of immune responders were compared using the Fisher's exact-test. Spearman rank correlations were used to estimate the force of the association between specific IgG in the MPB, IUCB and M3-infants' peripheral (M3) bloods.

\section{Results}

\section{Evolution of specific IgG and IgM levels during the first year of life}

At month 3 (M3), levels of specific gSG6-P1 IgG (Figure 1a) and IgM (Figure 1b) in the peripheral blood of infants were low [median IgG level $\left(\mathrm{M}_{\mathrm{IgG}}\right)=0.383$ and median IgM level $\left(\mathrm{M}_{\mathrm{IgM}}\right)=0.228$ ]. Importantly, these levels of IgG and IgM gradually increased from M3 to M12 $\left(\mathrm{M}_{\mathrm{IgG}}=0.721\right.$ and $\left.\mathrm{M}_{\mathrm{IgM}}=0.352\right)$, with intermediate values at $\mathrm{M} 6\left(\mathrm{M}_{\mathrm{IgG}}=0.527\right.$ and $\left.\mathrm{M}_{\mathrm{IgM}}=0.288\right)$ and $\mathrm{M} 9$ $\left(\mathrm{M}_{\mathrm{IgG}}=0.646\right.$ and $\left.\mathrm{M}_{\mathrm{IgM}}=0.326\right)$. The increase of specific IgG levels (Figure 1a) was significant between two successive sampled age periods: M3-M6 ( $<<0.0001)$, M6-M9 ( $<$ 0.0001) and M9-M12 ( $\mathrm{p}=0.002)$. Similarly, specific IgM levels (Figure 1b) significantly increased only between M3 and M6 ( $<$ 0.001) and M9-M12 ( $=0.03)$. No significant increase in specific IgM levels was noted between M6 and M9 ( $\mathrm{p}=0.085)$.

Interestingly, as observed for anti-gSG6-P1 IgG and IgM, the intensity of $P$. falciparum infection in infants (Figure 1c) and the predicted entomological risk of infant exposure to Anopheles bites (Figure 1d) were also low at M3 and increased from M3 to M12. However, the difference in the intensity of $P$. falciparum infection and the predicted entomological risk of exposure between any two consecutive age periods (M3-M6, M6-M9 and M9M12) were not significant, unlike that observed for antigSG6-P1 Ab levels.

The percentages of IgG and IgM responders were calculated for the four time-sampling dates (Table 1). Results show that by M3, 94\% of the infants were IgG 


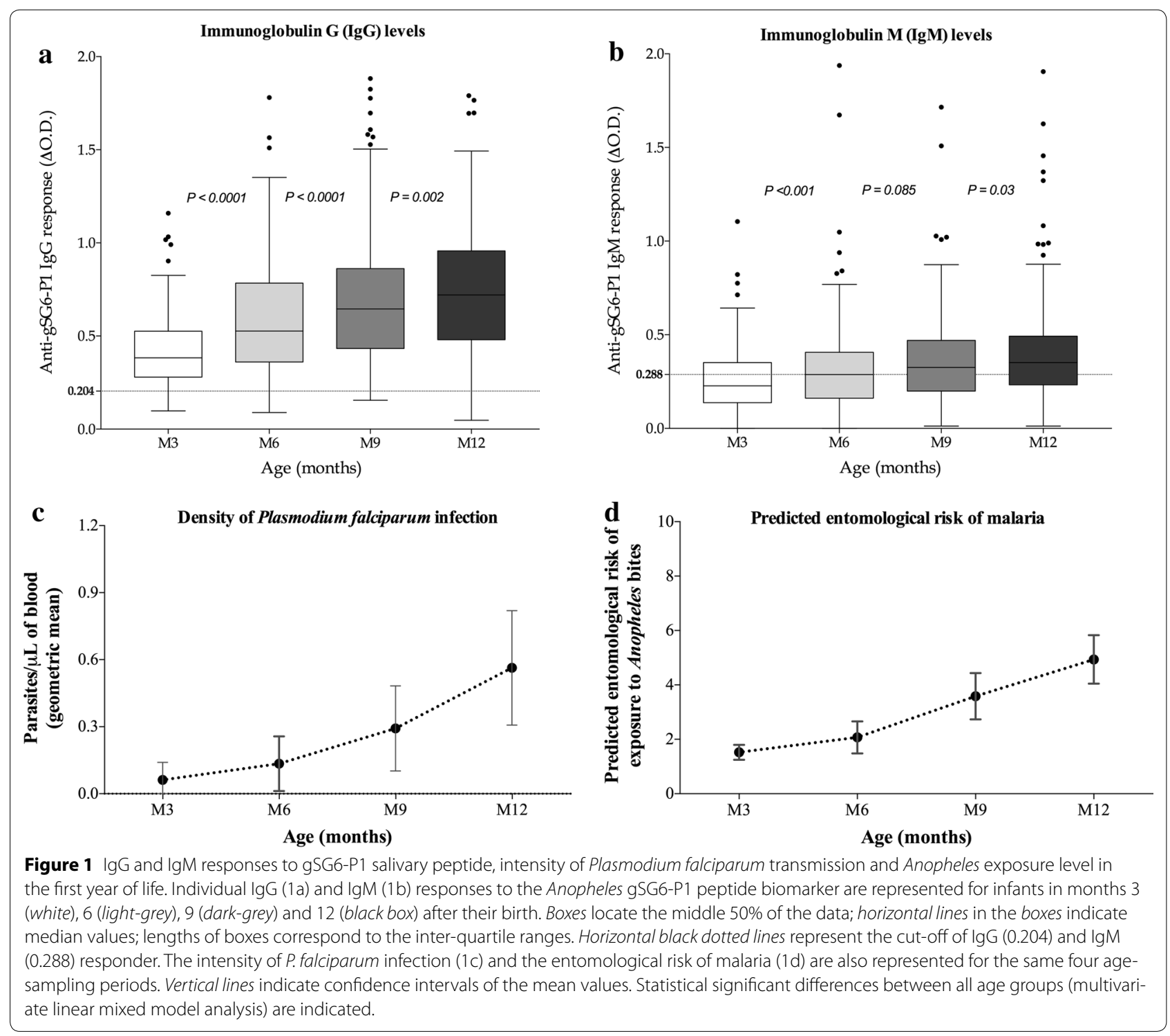

Table 1 Percentages of IgG and IgM responders according to age and the place of birth/residence

\begin{tabular}{llll}
\hline Variables & Groups & \multicolumn{2}{l}{ Individual Ab responders to gSG6-P1 peptide } \\
\cline { 3 - 4 } & & Percentage (\%) of IgG responders & Percentage (\%) of IgM responders \\
\hline Age & M3 & $93.98(125 / 133)$ & $41.35(55 / 133)$ \\
& M6 & $97.74(130 / 133)$ & $50.37(67 / 133)$ \\
& M9 & $98.96(131 / 133)$ & $56.39(75 / 133)$ \\
Maternity hospitals & M12 & $98.96(131 / 133)$ & $65.41(87 / 133)$ \\
& Avame & $97.87(230 / 235)$ & $17.02(40 / 235)$ \\
& Gare & $93.11(108 / 116)$ & $89.65(104 / 116)$ \\
& Cada & $98.37(181 / 184)$ & $76.63(141 / 184)$
\end{tabular}

The place of birth/residence was studied by combining infants of all ages $(n=532)$. 
responders, and this increased to $98 \%$ by M6 and to $99 \%$ by M9-M12. The percentage of IgM responders was lower at M3 (41\%), and gradually increased to $65 \%$ by M12 with values of $50 \%$ at M6 and $56 \%$ at M9.

\section{Specific gSG6-IgG levels according to maternity hospital of delivery}

Assuming that each pregnant woman delivered her baby at the closest maternity hospital, Immunological data were analysed based on the hospital of delivery. Avame, Gare and Cada received pregnant women from three (Avame centre, Gbedjougo and Houngo), two (Dohinoko and Gbetaga) and four villages (Anavie, Cada, Zebe and Zoungoudo), respectively. The M3 levels of IgG and IgM (Figure 2) and the percentage of IgM responders at M3 (Table 1) were lower in Avame compared to Gare ( $\mathrm{p}=0.0013, \mathrm{p}<0.0001$ and $\mathrm{p}<0.0001$, respectively) or to Cada ( $<<0.0001$ for all three), although the percentage of IgG responders (Table 1) was not significantly different among the three locations of birth. Median IgG levels did not differ between Gare and Cada ( $p=0.47)$, in contrast to the median IgM levels, which were higher in Gare $(\mathrm{p}=0.0008)$.

The profile of median of specific Ab levels during the first life year was similar in the three MHs: a gradual increase from M3 to M12 (Figure 2). However, some differences between two successive age-sampling periods were observed. In detail, in Avame (Figure 2a) where antigSG6-P1 Ab responses were lower, IgG levels increased significantly between M3 and M6 ( $\mathrm{p}<0.0001)$, M6-M9 $(\mathrm{p}<0.0001)$, M9-M12 ( $<0.05)$, and IgM levels between M3 and M6 (p < 0.05), M9-M12 (p < 0.01). However, IgG and IgM levels significantly increased only between M3 and M6 in Gare ( $<0.001$ for IgG; Figure 2b) and in Cada $(\mathrm{p}<0.0001$ and $\mathrm{p}<0.001$ respectively; Figure $2 \mathrm{c})$.

Age, intensity of Plasmodium falciparum infection, use of vector control and exposure to Anopheles bites: main factors of variation of anti-gSG6-P1 IgG and IgM levels Independent of location and individual cofactors (random intercepts at individual and village levels), both individual IgG and IgM responses to gSG6-P1 were 20 and $8 \%$ higher at M6 (regression coefficient $(\mathrm{RE})=1.20$ and $\mathrm{p}<0.0001, \mathrm{RE}=1.08$ and $\mathrm{p}=0.0117$, respectively), 34 and $12 \%$ at $\mathrm{M} 9(\mathrm{RE}=1.34$ and $\mathrm{p}<0.0001, \mathrm{RE}=1.12$ and $\mathrm{p}<0.0001$, respectively) and 39 and $16 \%$ at $\mathrm{M} 12$ $(\mathrm{RE}=1.39$ and $\mathrm{p}<0.0001, \mathrm{RE}=1.16$ and $\mathrm{p}<0.0001$, respectively) compared to M3 (Table 2). Specific IgG and IgM levels were also positively associated with the density of $P$. falciparum infection $(\mathrm{RE}=1.03$ and $\mathrm{p}=0.0065$, $\mathrm{RE}=1.03$ and $\mathrm{p}=0.0037$, respectively). In contrast,
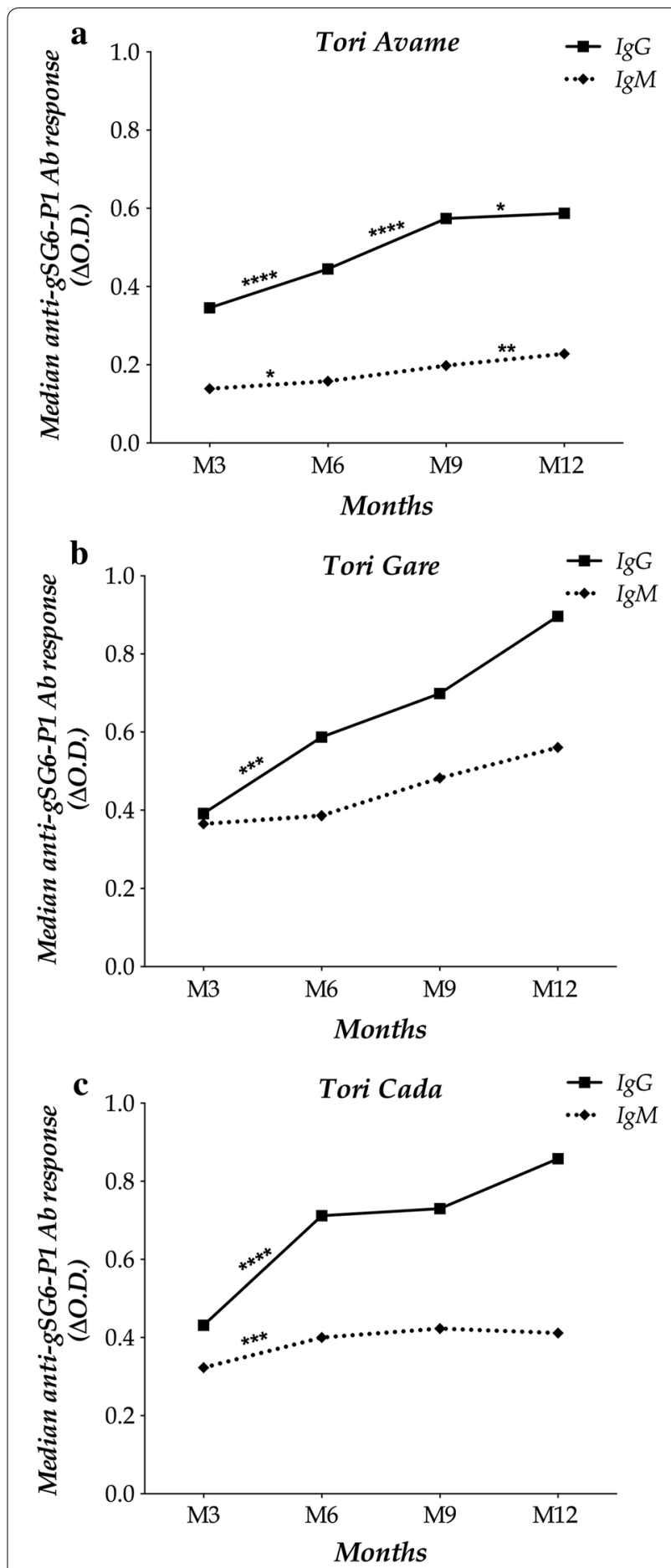

Figure 2 Evolution of gSG6-P1-specific lgG and IgM in the maternity hospital of infants' birth. The evolution of IgG (solid line) and IgM (dotted line) responses to gSG6-P1 Anopheles antigen is represented for infants in Tori Avame (a), Tori Gare (b) and Tori Cada (c). The significance level of the difference of specific Ab level between two successive age-periods is indicated by "**" ("*", "***" and ${ }^{\prime * * * *}$ mean $p<0.05$, $p<0.001$ and $p<0.0001$, respectively). 
Table 2 Linear Mixed-Effects (LME) model to study anti-gSG6-P1 response according to age, gender, seasonality, vector control, location and Plasmodium falciparum infection

\begin{tabular}{|c|c|c|c|c|}
\hline & \multicolumn{2}{|l|}{ Anti-gSG6-P1 lgG response } & \multicolumn{2}{|l|}{ Anti-gSG6-P1 IgM response } \\
\hline & Estimated coefficient (SE) & P-value & Estimated coefficient (SE) & P-value \\
\hline \multicolumn{5}{|l|}{ Fixed effects } \\
\hline Intercept & $0.57(0.09)$ & 0.0000 & $0.36(0.06)$ & 0.0000 \\
\hline \multicolumn{5}{|l|}{ Age (months) } \\
\hline $3(n=133)$ & - & - & - & - \\
\hline $6(n=133)$ & $0.184(0.024)$ & 0.0000 & $0.081(0.025)$ & 0.0117 \\
\hline $9(n=133)$ & $0.289(0.025)$ & 0.0000 & $0.110(0.026)$ & 0.0000 \\
\hline $12(n=133)$ & $0.327(0.026)$ & 0.0000 & $0.152(0.026)$ & 0.0000 \\
\hline \multicolumn{5}{|l|}{ Season } \\
\hline Dry season 1 & - & - & - & - \\
\hline Dry season 2 & $0.57(0.09)$ & 0.1445 & $-0.001(0.028)$ & 0.9561 \\
\hline Rain season 1 & $0.57(0.09)$ & 0.3689 & $-0.040(0.044)$ & 0.3590 \\
\hline Rain season 2 & $0.57(0.09)$ & 0.7927 & $-0.029(0.030)$ & 0.3218 \\
\hline \multicolumn{5}{|l|}{ Vector control } \\
\hline No ITN & - & - & - & - \\
\hline ITN & $-0.075(0.025)$ & 0.0037 & $-0.023(0.027)$ & 0.3904 \\
\hline \multicolumn{5}{|l|}{ Plasmodium prevalence } \\
\hline Not infected & - & - & - & - \\
\hline Infected & $0.016(0.064)$ & 0.8084 & $0.089(0.068)$ & 0.1943 \\
\hline Plasmodium density & $0.031(0.011)$ & 0.0065 & $0.031(0.010)$ & 0.0037 \\
\hline Entomological risk of exposure & $-0.003(0.004)$ & 0.4677 & $0.009(0.005)$ & 0.0578 \\
\hline \multicolumn{5}{|l|}{ Random effects } \\
\hline Village level & $0.074(0.045)$ & - & $0.091(0.086)$ & - \\
\hline Individual level & $0.241(0.183)$ & - & $0.157(0.202)$ & - \\
\hline
\end{tabular}

The classes of variables with significant $p$ value are highlighted in italic

The intercept is the constant value when all independent variables are zeros (e.g. the value of median Ab response in someone with no risk factors). Random effects of the model were estimated at individual and village levels in the form of standard deviation. The estimated coefficient, its confidence interval and the degree of signification (P-value) are indicated. A positive regression coefficient means that the explanatory variable increases the probability of Ab response to gSG6-P1, while a negative regression coefficient means the contrary.

anti-gSG6-P1 IgG responses significantly decreased with the use of vector control (ITNs) $(\mathrm{RE}=0.47$ and $\mathrm{p}=0.0037$ ). Finally, no significant variation of specific gSG6-P1 IgG or IgM levels was observed according to seasonality, the predictive risk of exposure to malaria or the prevalence of infection with P. falciparum (Table 2).

\section{Evidence of mother-to-child transmission of anti-gSG6-P1 $\lg G$}

As mentioned before, the percentage of specific IgG responders was surprisingly high (93.98\%), and considerably higher $(\mathrm{p}<0.0001)$ than that of anti-gSG6-P1 IgM responders $(41.35 \%)$. In addition, a positive association was observed between specific IgG levels in the MPB and the IUCB (Spearman R $=0.73$; $p<0.0001$; Figure 3a), in the IUCB and the peripheral blood of M3-infants $(R=0.43 ; p<0.0001$; Figure $3 b)$, and in the $\mathrm{MPB}$ and the peripheral blood of M3-infants $(\mathrm{R}=0.34$; $\mathrm{p}<0.0001$; Figure 3c). Moreover, a positive association was observed between specific IgG levels in the MPB and the M3-infant bloods in Avame (Spearman $\mathrm{R}=0.36$; $\mathrm{p}=0.006)$ and Cada $(\mathrm{R}=0.40 ; \mathrm{p}=0.005)$, and not in Gare $(\mathrm{R}=0.07 ; \mathrm{p}=0.7)$.

\section{Discussion}

This study reports the presence of IgG and IgM Ab specific to gSG6-P1, a salivary biomarker of Anopheles bites, in the blood of Beninese infants. A major point is that levels of such IgG and IgM responses gradually increased from three to 12 months of age, in parallel with the intensity of infection with P. falciparum and the predicted entomological risk of exposure to Anopheles bites. These data extend to infants the utility of such a biomarker and show also that mother-to-child transplacental transfer of IgG specific to a salivary protein of a blood-feeding arthropod occurs. This transfer, however, could cause an overestimate of the risk of malaria exposure or transmission during early childhood in a high endemic malaria area. 

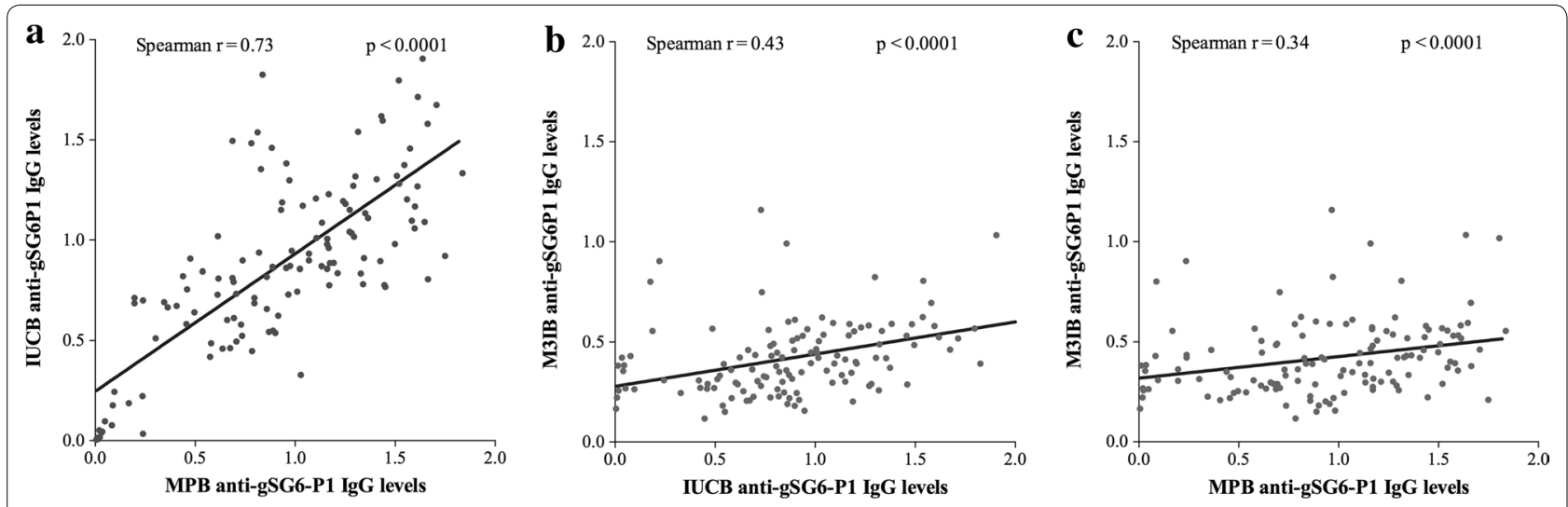

Figure 3 Correlations between specific lgG levels in the mothers' peripheral blood, umbilical cord blood and blood of M3-infants. Anti-gSG6-P1 lgG individual levels (black points) in the mothers' peripheral blood (MPB) are correlated to those detected in the infants' umbilical cord (IUCB; Figure 2a) and in the M3-infants' blood (Figure 2c). Specific lgG in the IUCB are correlated to those in M3-infant blood (Figure 2b). The black solid line indicates the correlation line. The significance of the linear association between two compared parameters is indicated (Spearman correlation method).

In the study, anti-gSG6-P1 IgG and IgM Ab were detected in respectively 93.98 and $41.35 \%$ of infants at 3 months (M3) of age. Anopheles mosquitoes then early bite the majority of infants in these localities of south Benin. However, the pressure of mosquito bites they were exposed to at 3 months was not high, as pointed by the low median values of IgG $(\mathrm{M}=0.383$, slightly upper the ' $\mathrm{TR}_{\mathrm{IgG}}$ ') and $\operatorname{IgM}\left(\mathrm{M}=0.228\right.$, under the $\left.\mathrm{TR}_{\mathrm{IgM}}\right)$. These 'low' endogenous M3-levels of plasma specific antibodies were not surprising, in that the newborn immune system is relatively considered as immature during early infancy [39-41]. In endemic malaria areas, young infants are progressively exposed to Anopheles bites, their salivary antigens, and eventually the Plasmodium spp. they carry [42]. This is suggested by the correlation observed between anti-gSG6-P1 Ab and both the intensity of infection with $P$. falciparum and the entomological risk of infant exposure to Anopheles bites [22, 26, 28, 33].

Specific IgG and IgM levels significantly differed based on the location of residence, suggesting spatial differences in human-Anopheles contact levels. Infants in the Avame area had lower specific IgG and IgM responses and presumably a lower contact level with Anopheles during their first year of life. This can be linked to a likely lower aggressiveness of Anopheles in this area, a higher protection level against vectors or different household characteristics (type, well-closed doors and windows) [22, 31-33, 38]. This might explain the slower gradual increase of specific IgG and IgM in Avame compared to Cada and Gare. The role of individual factors (genetic background, nutritional status or nocturnal activities) in that differential gradual acquisition cannot be excluded $[37,43,44]$. All this means that infants were more highly bitten by mosquitoes, acquired more rapidly maturity of immune system and synthetized more specific antibodies in Gare settings than in Avame and Cada.

Maternal IgG is provided to the infant by transplacental transport $[9,45]$. This study describes the evidence of a mother-infant transplacental transfer of anti-gSG6-P1 IgG, contributing to the high percentage of IgG infant responders at 3 months of age (about 94\%). Maternal blood concentrations of specific IgG were positively correlated with respective umbilical cord and three-month old infant blood values. In addition, higher specific IgG levels were found in the maternal and cord blood of M3-infants with higher IgG titers, suggesting that the quantity of transferred specific IgG is dependent on the level in the mother that likely reflects the level of maternal exposure to Anopheles bites. Despite this positive association, maternal levels of specific IgG transfer could not accurately predict the level of infant specific IgG. In addition, such transfer also depends on the placental integrity, IgG subclass and nature of antigen $[9,46]$. Unfortunately, investigating the effects of such factors was not possible in this study.

For a reliable evaluation of the young infant-Anopheles contact level by using anti-gSG6-P1 IgG, the proportion contributed from the mother must be considered. The linear regression analysis has estimated about 52 and $21 \%$ of the maternal gSG6-P1-specific IgG found in blood of newborns just after delivery and at 3 months of life, respectively, indicating a rapid decline of maternally transferred IgG $[47,48]$. It also suggests that maternally transferred IgG are probably cleared in the blood of infants by 6 months of age, suggesting that anti-gSG6-P1 IgG should be more relevant as biomarker of infant exposure to mosquito bites after 6 months of age. Another possibility would be to distinguish maternal and neonatal 
specific Ab in infant plasma by mass spectrometry [49], but such technology is unavailable in resource-limited countries. The third approach would be to use IgM Ab that form polymers (usually pentamers) in humans and does not cross the maternal-feta barrier $[9,50]$. Interestingly, the M3 proportion of infants presenting IgM against gSG6-P1 peptide (41.35\%) was significantly lower than the percentage of those with specific IgG (93.98\%). In addition, the highest percentage of IgM responders (89.65\%) was obtained in Gare areas, where levels of mother specific IgG were not correlated to levels of IgG of their M3-infants, contrary to Avame and Cada areas. Moreover, no differences in IgM levels or percentage of responders were observed between two successive sampling ages after 6 months of age, in contrast to IgG levels. In infants older than 6 months, specific IgG levels were better at assessing exposure to Anopheles bites and the risk of malaria transmission. One hypothesis is that, depending on the level of exposure to mosquito bites, the initial anti-Anopheles saliva IgM response may have failed to switch to IgG after several weeks or months as has been shown previously for responses to $P$. falciparum antigens $[50,51]$. Nevertheless, the kinetics of IgG (and subclasses) and IgM responses to gSG6-P1 salivary peptide must be elucidated in additional studies.

\section{Conclusion}

In summary, individual exposure levels to Anopheles mosquito bites and therefore the risk for malaria transmission in early infancy has been described in a malariaendemic area of Benin. Moreover, because of transfer of IgG specific to salivary gSG6-P1 Anopheles peptide from mother to infant there may be an overestimation of the utility of such a 'biomarker' early in infancy (less than 3 months). To overcome that potential challenge, specific IgM and IgG isotypes may be assayed for in infants younger and older than 6 months, respectively.

\begin{abstract}
Authors' contributions
$F R, A G, D C, A M$, and FMN designed the study. PMD, AP, SC, and FR conceived and designed the experiments. RL and CD collected the samples. PMD and MF performed the experiments. PMD analysed the data. PMD and FR wrote the paper. AP, CD, GC, AM, SC, DC, FMN, and AG reviewed the paper. All authors read and approved the final manuscript.
\end{abstract}

\footnotetext{
Author details

1 UMR MIVEGEC (IRD224-CNRS5290-Universités Montpellier 1 et 2), Institut de Recherche pour le Développement (IRD), BP64501, 34394 Montpellier, France. ${ }^{2}$ IRD-UMR MIVEGEC (IRD224-CNRS5290-Universités Montpellier 1 et 2), Centre de Recherche Entomologique de Cotonou (CREC), 01 BP 4414RP, Cotonou, Benin. ${ }^{3}$ IRD UMR 216 Mère et enfant face aux infections tropicales, 75006 Paris, France. ${ }^{4}$ Faculté de Pharmacie, Université Paris Descartes, Sorbonne Paris Cité, 75006 Paris, France. ${ }^{5}$ Laboratoire de Mathématiques Appliquées, Université Paris Descartes, 75006 Paris, France. ${ }^{6}$ Centre d'Etudes et de Recherche sur le Paludisme Associé à la Grossesse et à l'Enfant (CERPAGE), Cotonou, Benin. ${ }^{7}$ Faculté des Sciences de la Santé, Université d'Abomey-Calavi, 01 BP 188,
}

Cotonou, Benin. ${ }^{8}$ Present Address: Laboratory of Parasitic Diseases, NIAID, NIH, 4 Center Dr, Bethesda, MD 20892-0425, USA.

\section{Acknowledgements}

We thank Thomas B Nutman (NIH) for the language review and re-editing of the manuscript. We thank populations of Tori Bossito, especially women, for their great support and collaboration. We also thank all the field and laboratory staff for their strong commitment to this project. Funding received from the French Ministry of Foreign Affairs and the IRD provided all of the funds for this study.

\section{Compliance with ethical guidelines}

\section{Competing interests}

The authors declare that they have no competing interests.

Received: 22 April 2015 Accepted: 3 July 2015

Published online: 22 July 2015

\section{References}

1. Aponte JJ, Schellenberg D, Egan A, Breckenridge A, Carneiro I, Critchley J et al (2009) Efficacy and safety of intermittent preventive treatment with sulfadoxine-pyrimethamine for malaria in African infants: a pooled analysis of six randomised, placebo-controlled trials. Lancet 374:1533-1542

2. Eastman RT, Fidock DA (2009) Artemisinin-based combination therapies: a vital tool in efforts to eliminate malaria. Nat Rev Microbiol 7:864-874

3. Lengeler C (2004) Insecticide-treated bed nets and curtains for preventing malaria. Cochrane Database Syst Rev CD000363

4. Barnes KI, Durrheim DN, Little F, Jackson A, Mehta U, Allen E et al (2005) Effect of artemether-lumefantrine policy and improved vector control on malaria burden in KwaZulu-Natal, South Africa. PLoS Med 2:e330

5. Cotter C, Sturrock HJ, Hsiang MS, Liu J, Phillips AA, Hwang J et al (2013) The changing epidemiology of malaria elimination: new strategies for new challenges. Lancet 382:900-911

6. Noor AM, Kinyoki DK, Mundia CW, Kabaria CW, Mutua JW, Alegana VA et al (2014) The changing risk of Plasmodium falciparum malaria infection in Africa: 2000-10: a spatial and temporal analysis of transmission intensity. Lancet 383:1739-1747

7. WHO (2014) World malaria report. World Health Organization, Geneva

8. Le Port A, Watier L, Cottrell G, Ouedraogo S, Dechavanne C, Pierrat C et al (2011) Infections in infants during the first 12 months of life: role of placental malaria and environmental factors. PLoS One 6:e27516

9. Palmeira P, Quinello C, Silveira-Lessa AL, Zago CA, Carneiro-Sampaio M (2012) IgG placental transfer in healthy and pathological pregnancies. Clin Dev Immunol 2012:985646

10. Le Port A, Cottrell G, Martin-Prevel Y, Migot-Nabias F, Cot M, Garcia A (2012) First malaria infections in a cohort of infants in Benin: biological, environmental and genetic determinants. Description of the study site, population methods and preliminary results. BMJ Open 2:e000342

11. Beier JC, Killeen GF, Githure JI (1999) Entomologic inoculation rates and Plasmodium falciparum malaria prevalence in Africa. Am J Trop Med Hyg 61:109-113

12. Drakeley CJ, Corran PH, Coleman PG, Tongren JE, McDonald SL, Carneiro I et al (2005) Estimating medium- and long-term trends in malaria transmission by using serological markers of malaria exposure. Proc Natl Acad Sci USA 102:5108-5113

13. Poinsignon A, Cornelie S, Mestres-Simon M, Lanfrancotti A, Rossignol M, Boulanger D et al (2008) Novel peptide marker corresponding to salivary protein gSG6 potentially identifies exposure to Anopheles bites. PLoS One 3:e2472

14. Govella NJ, Chaki PP, Geissbuhler Y, Kannady K, Okumu F, Charlwood JD et al (2009) A new tent trap for sampling exophagic and endophagic members of the Anopheles gambiae complex. Malar J 8:157

15. Mboera LE (2005) Sampling techniques for adult Afrotropical malaria vectors and their reliability in the estimation of entomological inoculation rate. Tanzan Health Res Bull 7:117-124 
16. The MalERA Consultative group on Monitoring EaS (2011) A research agenda for malaria eradication: monitoring, evaluation, and surveillance. PLOS Med 8:e1000400

17. WHO (2009) Global malaria action plan. World Health Organization, Geneva

18. Ribeiro JM, Francischetti IM (2003) Role of arthropod saliva in blood feeding: sialome and post-sialome perspectives. Annu Rev Entomol 48:73-88

19. Fontaine A, Diouf I, Bakkali N, Misse D, Pages F, Fusai T et al (2011) Implication of haematophagous arthropod salivary proteins in host-vector interactions. Parasit Vectors 4:187

20. Champagne DE (2004) Antihemostatic strategies of blood-feeding arthropods. Curr Drug Targets Cardiovasc Haematol Disord 4:375-396

21. Ribeiro JM (1995) Blood-feeding arthropods: live syringes or invertebrate pharmacologists? Infect Agents Dis 4:143-152

22. Drame PM, Machault V, Diallo A, Cornelie S, Poinsignon A, Lalou R et al (2012) IgG responses to the gSG6-P1 salivary peptide for evaluating human exposure to Anopheles bites in urban areas of Dakar region, Senegal. Malar J 11:72

23. Orlandi-Pradines E, Almeras L, de Denis Senneville L, Barbe S, Remoue F, Villard C et al (2007) Antibody response against saliva antigens of Anopheles gambiae and Aedes aegypti in travellers in tropical Africa. Microbes Infect 9:1454-1462

24. Reunala T, Brummer-Korvenkontio H, Lappalainen P, Rasanen L, Palosuo T (1990) Immunology and treatment of mosquito bites. Clin Exp Allergy 20(Suppl 4):19-24

25. King JG, Vernick KD, Hillyer JF (2011) Members of the salivary gland surface protein (SGS) family are major immunogenic components of mosquito saliva. J Biol Chem 286:40824-40834

26. Remoue F, Cisse B, Ba F, Sokhna C, Herve JP, Boulanger D et al (2006) Evaluation of the antibody response to Anopheles salivary antigens as a potential marker of risk of malaria. Trans R Soc Trop Med Hyg 100:363-370

27. Andrade BB, Rocha BC, Reis-Filho A, Camargo LM, Tadei WP, Moreira LA et al (2009) Anti-Anopheles darlingi saliva antibodies as marker of Plasmodium vivax infection and clinical immunity in the Brazilian Amazon. Malar J 8:121

28. Drame PM, Poinsignon A, Besnard P, Le Mire J, Dos-Santos MA, Sow CS et al (2010) Human antibody response to Anopheles gambiae saliva: an immuno-epidemiological biomarker to evaluate the efficacy of insecticide-treated nets in malaria vector control. Am J Trop Med Hyg $83: 115-121$

29. Rizzo C, Ronca R, Fiorentino G, Verra F, Mangano V, Poinsignon A et al (2011) Humoral response to the Anopheles gambiae salivary protein gSG6: a serological indicator of exposure to Afrotropical malaria vectors. PLoS One 6:e17980

30. Waitayakul A, Somsri S, Sattabongkot J, Looareesuwan S, Cui L, Udomsangpetch R (2006) Natural human humoral response to salivary gland proteins of Anopheles mosquitoes in Thailand. Acta Trop 98:66-73

31. Drame PM, Poinsignon A, Besnard P, Cornelie S, Le Mire J, Toto JC et al (2010) Human antibody responses to the Anopheles salivary gSG6-P1 peptide: a novel tool for evaluating the efficacy of ITNs in malaria vector control. PLoS One 5:e15596

32. Poinsignon A, Cornelie S, Ba F, Boulanger D, Sow C, Rossignol M et al (2009) Human IgG response to a salivary peptide, gSG6-P1, as a new immuno-epidemiological tool for evaluating low-level exposure to Anopheles bites. Malar J 8:198

33. Poinsignon A, Samb B, Doucoure S, Drame PM, Sarr JB, Sow C et al (2010) First attempt to validate the gSG6-P1 salivary peptide as an immuno-epidemiological tool for evaluating human exposure to Anopheles funestus bites. Trop Med Int Health 15:1198-1203

34. Drame PM, Diallo A, Poinsignon A, Boussari O, Dos Santos S, Machault $\checkmark$ et al (2013) Evaluation of the effectiveness of malaria vector control measures in urban settings of Dakar by a specific anopheles salivary biomarker. PLoS One 8:e66354

35. Damien GB, Djenontin A, Rogier C, Corbel V, Bangana SB, Chandre F et al (2010) Malaria infection and disease in an area with pyrethroid-resistant vectors in southern Benin. Malar J 9:380

36. Djenontin A, Bio-Bangana S, Moiroux N, Henry MC, Bousari O, Chabi J et a (2010) Culicidae diversity, malaria transmission and insecticide resistance alleles in malaria vectors in Ouidah-Kpomasse-Tori district from Benin (West Africa): A pre-intervention study. Parasit Vectors 3:83
37. Le Port A, Cottrell G, Martin-Prevel Y, Migot-Nabias F, Cot M, Garcia A (2012) First malaria infections in a cohort of infants in Benin: biological, environmental and genetic determinants. Description of the study site, population methods and preliminary results. BMJ Open 2:e000342

38. Cottrell G, Kouwaye B, Pierrat C, Le Port A, Bouraima A, Fonton N et al (2012) Modeling the influence of local environmental factors on malaria transmission in Benin and its implications for cohort study. PLoS One 7:e28812

39. Ellinger I, Fuchs R (2012) HFcRn-mediated transplacental immunoglobulin $\mathrm{G}$ transport: protection of and threat to the human fetus and newborn. Wien Med Wochenschr 162:207-213

40. Lisciandro JG, van den Biggelaar AH (2010) Neonatal immune function and inflammatory illnesses in later life: lessons to be learnt from the developing world? Clin Exp Allergy 40:1719-1731

41. Martin R, Nauta AJ, Ben Amor K, Knippels LM, Knol J, Garssen J (2010) Early life: gut microbiota and immune development in infancy. Benef Microbes 1:367-382

42. Rogier C (2003) Childhood malaria in endemic areas: epidemiology, acquired immunity and control strategies (in French). Med Trop (Mars) 63:449-464

43. Carnevale P, Frezil JL, Bosseno MF, Le Pont F, Lancien J (1978) The aggressiveness of Anopheles gambiae A in relation to the age and sex of the human subjects (in French). Bull World Health Organ 56:147-154

44. Geissbuhler Y, Chaki P, Emidi B, Govella NJ, Shirima R, Mayagaya V et al (2007) Interdependence of domestic malaria prevention measures and mosquito-human interactions in urban Dar es Salaam, Tanzania. Malar J 6:126

45. Deloron P, Dubois B, Le Hesran JY, Riche D, Fievet N, Cornet M et al (1997) Isotypic analysis of maternally transmitted Plasmodium falciparum-specific antibodies in Cameroon, and relationship with risk of $P$. falciparum infection. Clin Exp Immunol 110:212-218

46. Costa-Carvalho BT, Vieria HM, Dimantas RB, Arslanian C, Naspitz CK, Sole D et al (1996) Transfer of IgG subclasses across placenta in term and preterm newborns. Braz J Med Biol Res 29:201-204

47. Andrade BB, Barral-Netto M (2011) Biomarkers for susceptibility to infection and disease severity in human malaria. Mem Inst Oswaldo Cruz 106(Suppl 1):70-78

48. De Serres G, Joly JR, Fauvel M, Meyer F, Masse B, Boulianne N (1997) Passive immunity against measles during the first 8 months of life of infants born to vaccinated mothers or to mothers who sustained measles. Vaccine 15:620-623

49. Leuridan E, Hens N, Hutse V, leven M, Aerts M, Van Damme P (2010) Early waning of maternal measles antibodies in era of measles elimination: longitudinal study. BMJ 340:C1626

50. Dechavanne C, Guillonneau F, Chiappetta G, Sago L, Lévy P, Salnot V et al (2012) Mass spectrometry detection of G3 m and IGHG3 alleles and follow-up of differential mother and neonate lgG3. PLoS One 7:e46097

51. Kinyanjui SM, Bull P, Newbold Cl, Marsh K (2003) Kinetics of antibody responses to Plasmodium falciparum-infected erythrocyte variant surface antigens. J Infect Dis 187:667-674

\section{Submit your next manuscript to BioMed Central and take full advantage of:}

- Convenient online submission

- Thorough peer review

- No space constraints or color figure charges

- Immediate publication on acceptance

- Inclusion in PubMed, CAS, Scopus and Google Scholar

- Research which is freely available for redistribution

Submit your manuscript at

www.biomedcentral.com/submit
( Biomed Central 